\title{
Significance of Rumex Vesicarius as Anticancer Remedy Against Hepatocellular Carcinoma: a Proposal-Based on Experimental Animal Studies
}

\author{
Abdelaaty A Shahat ${ }^{1,2}$, Mansour S Alsaid ${ }^{1}$, Soheir E Kotob ${ }^{3}$, Hanaa H Ahmed ${ }^{3}$
}

\begin{abstract}
Rumex vesicarius is an edible herb distributed in Egypt and Saudi Arabia. The whole plant has significant value in folk medicine and it has been used to alleviate several diseases. Hepatocellular carcinoma (HCC), the major primary malignant tumor of the liver, is one of the most life-threatening human cancers. The goal of the current study was to explore the potent role of Rumex vesicarius extract against $\mathrm{HCC}$ induced in rats. Thirty adult male albino rats were divided into 3 groups: (I): Healthy animals received orally $0.9 \%$ normal saline and served as negative control group, (II): HCC group in which rats were orally administered N-nitrosodiethylamine NDEA, (III): HCC group treated orally with $R$. vesicarius extract in a dose of $400 \mathrm{mg} / \mathrm{kg} \mathrm{b.wt} \mathrm{daily} \mathrm{for} \mathrm{two}$ months. ALT and AST, ALP and $\gamma$-GT activities were estimated. CEA, AFP, AFU, GPC-3, Gp-73 and VEGF levels were quantified. Histopathological examination of liver tissue sections was also carried out. The results of the current study showed that the treatment of the HCC group with $R$. vesicarius extract reversed the significant increase in liver enzymes activity, CEA, AFP, AFU, glypican 3, golgi 73 and VEGF levels in serum as compared to HCC-untreated counterparts. In addition, the favorable impact of $R$. vesicarius treatment was evidenced by the marked improvement in the histopathological features of the liver of the treated group. In conclusion, the present experimental setting provided evidence for the significance of $R$. vesicarius as anticancer candidate with a promising anticancer potential against HCC. The powerful hepatoprotective properties, the potent antiangiogenic activity and the effective antiproliferative capacity are responsible for the anticancer effect of this plant.
\end{abstract}

Keywords: Hepatocellular carcinoma - polygonaceae - R. vesicarius - angiogenesis - apoptosis - rats

Asian Pac J Cancer Prev, 16 (10), 4303-4310

\section{Introduction}

Anticancer therapy is one of the biggest challenges in medicine. Therefore, searching for highly efficient antitumor drugs remains a hot area of research. Plants and plant-based products are gaining importance against variety of diseases due to their non-toxic and no / less side effects. Hence, we have been continuously working on the identification and characterization of medicinal plants (Khan, 2012). Rumex vesicarius L. of the family Polygonaceae is an edible herb, locally called hummayed, growing as wild herb throughout desert and semi-desert areas of Saudi Arabia. R. vesicarius is widely used as food, as a medicinal herb and as an antidote to scorpion stings (Shahat et al., 2013). The medicinal importance of $R$. vesicarius is a reflection to its chemical composition since the plant contains many bioactive substances such as flavonoids, anthraquinons, carotenoids, vitamins, lipids and organic acids, which are known to be anticancer, antioxidant and antimicrobial agents (Barbosa et al., 2008; Imran et al., 2011). Of particular interest, It has been demonstrated that all plant parts contained quercetin in high amounts (Bakry et al., 2012). The intake of dietary antioxidants of plant origin like carotenoids, phenolic compounds and flavonoids may lead to the protection against non-communicable diseases in human beings such as cancer, cardiovascular diseases and cataract (Matkowski, 2008).

$R$. vesicarius has many important medicinal uses such as treatment of tumors, liver diseases, bad digestion, constipation, calcules, heart troubles, pains, diseases of the spleen, hiccough, flatulence, asthma, bronchitis, dyspepsia, piles, scabies, leucoderma, toothache and nausea. This plant is also used as laxative, stomachic, tonic, analgesic, appetizer, diuretic, astringent, purgative and antispasmodic. Moreover, can be used to reduce biliary disorders and control cholesterol levels (Lakshmi et al., 2009). The lipoid constituents of $R$. vesicarius 
were examined by both liquid chromatography/mass spectrometry (LC/MS) and by gas chromatography/mass spectrometry (GC/MS). Their essential oil compositions consisted mainly of thujene, limonene, fenchon, estragole, and anethole. The crude lipid extract and the methanol extract showed strong antioxidant activity and radical quenching potential against 2, 2-diphenyl1-picrylhydrazyl (DPPH) systems (Bakry et al., 2012; Elfotoh, et al., 2013).

Cancer is the leading cause of death around the world (Zeng et al., 2015). Cancer is, still a devastating disease, responsible for roughly one quarter of deaths and one of the most imminent health problems in the developed world and it continues to be a major disease for those in developed and developing countries. Cancer deserves a high priority of research owing to the large number of deaths, the enormous human suffering, and related health care. Hepatocellular carcinoma (HCC) is one of the major health burdens worldwide (Lyer et al., 2010) and is a leading cause of cancer death worldwide (Mitupatum et al., 2015). It is one of the most life-threatening human cancers in the world, resulting in almost one million deaths every year (Center and Jemal, 2011). HCC is the third leading cause of cancer deaths worldwide, with prevalence 16-32 times higher in developing countries. The incidence of HCC is higher in males than in females with the male: female ratio usually averaging between 2:1 and 4:1 (El-Serag and Rudolph, 2007). Also, the rising trend of $\mathrm{HCC}$ has been associated with increased prevalence of hepatitis $\mathrm{C}$ virus $(\mathrm{HCV})$ infection (Serag, 2002). Lingering infection with hepatitis B virus (HBV) and hepatitis $\mathrm{C}$ virus (HCV) represents the major risk factor for HCC (Gao et al., 2012). In Egypt, HCC is the second most common malignancy in males and the fifth in the females. Egypt has the highest prevalence of hepatitis $\mathrm{C}$ virus in the world with an average of approximately $13.8 \%$ in the general population (Deuffic et al., 2006). The major risk factor of $\mathrm{HCC}$ is infection by $\mathrm{HCV}$, which accounts for $20 \%$ of acute hepatitis, $70 \%$ of chronic hepatitis, $40 \%$ of cirrhosis and up to $90 \%$ of HCC cases (Hosny et al., 2008). Lack of effective diagnostic tools for early detection and limited treatment options for patients with advanced HCC contribute to a dismal prognosis coupled with high mortality for this disease (Thomas et al., 2010; Bishayee, 2012).

Diethylnitrosamine (NDEA) is found in a wide variety of foods and beverages such as cheese, soybeans, smoked, salted and dried fish, cured meat, alcoholic beverages as well as in ground water having a high level of nitrates (Liao et al., 2001). In rats, NDEA is a potent hepatocarcinogen influencing the initiation stage of carcinogenesis during a period of enhanced cell proliferation accompanied by hepatocellular necrosis. NDEA induces DNA carcinogen adducts, DNA-strand breaks and in turn hepatocellular carcinomas without cirrhosis through the development of putative preneoplastic focal lesions (Ahmed et al., 2010). Anticancer activities from many functional food sources have been reported in years, but correlation between cancer prevalence and types of food with anticancer activities from crop origin center in the world as well as food source with human migration are unclear (Zeng et al., 2015). The current study was undertaken to elucidate the anticancer potential of $R$. vesicarius extract against diethylnitrosamine-induced hepatocellular carcinoma in male rats with special concern on its mechanism of action.

\section{Materials and Methods}

\section{Chemicals}

N-nitrosodiethylamine (NDEA) (CAS no. 55-18-5) was purchased from Sigma-Aldrich Chemicals Co. (St Louis, MO, USA). All other chemicals and solvents were of analytical grade.

\section{Plant material}

Rumex vesicarius was collected from the different area of the campus of the plants of King Saud University, Riyadh, Saudi Arabia in April 2012. The plant was identified by the Plant Taxonomist at the Herbarium Unit. The voucher specimens (15936) was deposited at the Herbarium of the Faculty of Pharmacy, King Saud University, Riyadh, Saudi Arabia

\section{Plant extraction}

The plant was collected and the aerial part was dried under shade. The dried samples were powdered and used for solvent extraction. For extract preparation, $1.2 \mathrm{~kg}$ of dried sample was extracted twice with $3 \mathrm{~L}$ of $80 \%$ methanol. The extracts were filtered through Whatman No.1 filter paper and concentrated using a rotary evaporator under reduced pressure at $40^{\circ} \mathrm{C}$ to obtain residue with yields of $13 \%$

\section{Experimental set up}

A total number of thirty adult male rats of Wistar strain weighing $170-200 \mathrm{~g}$ were used in the present work. The animals were obtained from the Animal House Colony of the National Research Centre, Giza, Egypt. The rats were housed in polypropylene cages in an environmentally controlled clean air room with a temperature of $25 \pm 1^{\circ} \mathrm{C}$, an alternating $12 \mathrm{~h}$ light $/ 12 \mathrm{~h}$ dark cycle, a relative humidity of $60 \pm 5 \%$ and free access to tap water and a standard rodent chow (Wadi El Kabda Co., Cairo, Egypt). The rats were allowed to adapt to these conditions for 2 weeks before starting the experimental set-up. The experimental protocol was approved by the Ethical Committee for Medical Research, National Research Centre, Egypt. After the acclimatization period, the animals were divided into three groups of equal average body weight and kept in well ventilated caged. They were labeled namely group i): Normal healthy animals received orally $0.9 \%$ normal saline and served as negative control group, group ii): HCC group in which the rats were orally administered with N-nitrosodiethylamine (NDEA) (dissolved in $0.9 \%$ normal saline), in a dose of $20 \mathrm{mg} / \mathrm{kg}$ b.wt. five times weekly for six weeks according to the modified method of Darwish and El-Boghdady (2011) and group iii) HCC-treated group in which the rats were treated orally with $R$. vesicarius extract in a dose of $400 \mathrm{mg} / \mathrm{kg}$ b.wt (Raghavendra and Reddy, 2011) daily for two months. 
Significance of Rumex Vesicarius as Anticancer Remedy against Hepatocellular Carcinoma: an Experimental Animal Study

Samples collection

After the completion of this round, the animals were fasted overnight and the blood samples were collected, under diethyl ether anesthesia, from the retroorbital venous plexus in a dry clean centrifuge tubes and allowed to coagulate for 45 minutes at room temperature to obtain sera to be used for biochemical analyses. Clear serum samples were separated by centrifugation at $1800 \mathrm{xg}$ for 15 minutes at $4^{\circ} \mathrm{C}$ using cooling centrifuge. Serum samples were stored at $-20^{\circ} \mathrm{C}$ pending further biochemical analyses. After collection of the blood samples, the animals were sacrificed by cervical dislocation and the liver specimens from experimental animals were quickly excised, rinsed with saline and fixed in $10 \%$ formalin saline solution for histological examination.

\section{Biochemical analyses}

Serum alanine aminotransferase (ALT) and asparatate aminotransferase (AST) activities were estimated using colorimetric kit purchased from Salucea Co. Ltd (Netherlands) according to ECCLS (1989) method. Serum alkaline phosphatase (ALP) and gamma-glutamyl transferase $(\gamma-\mathrm{GT})$ activities were determined using colorimetric kit purchased from Reactivos GPL Co. Ltd (Barcelona) according to Tietz (1995) method. Serum carcinoembyronic (CEA) was quantified by enzyme linked immunosorbent assay (ELISA) technique using a kit purchased from Immunospec Co., Ltd (USA), according to Schwartz (1987) method. Serum alpha-fetoprotein (AFP) level was measured by ELISA technique using ELISA kit purchased from Immunospec Co., Ltd (USA), according to the method of Hirai (1982). Serum alphaL-fucosidase (AFU) activity was evaluated by ELISA technique using a kit purchased from Glory Science Co., Ltd (USA), according to the manufacturer's instructions provided with AFU assay kit. Serum glypican-3 (GPC3) level was assayed by ELISA technique using a kit purchased from Glory Science Co., Ltd (USA), according to the manufacturer's instructions provided with GPC3 assay kit. Serum golgi protein 73 (Gp-73) level was detected by ELISA technique using a kit purchased from Glory Science Co., Ltd (USA), according to the manufacturer's instructions provided with Gp-73 assay kit. Serum vascular endothelial growth factor (VEGF) level was estimated by ELISA technique using a kit purchased from Glory Science Co., Ltd (USA), according to the manufacturer's instructions provided with VEGF assay kit.

\section{Histopathological examination}

After fixation of the liver specimens in formal saline
(10\%) for 24 hours, the tissues were washed in running tap water and dehydrated in series of alcohol (methyl, ethyl and absolute alcohol). The specimens were cleared in xylene and embedded in paraffin at 56 degree in hot air oven for twenty four hours. The paraffin wax tissue blocks were sectioned by slidge microtome at thickness of $4 \mu \mathrm{m}$. The obtained tissue sections were collected on clean glass slides and left in the oven at $40^{\circ} \mathrm{C}$ for dryness before examination under the light electric microscope (Banchroft et al., 1996).

\section{Statistical analysis}

The experimental results were represented as arithmetic means with their standard errors. Data were analyzed by one way analysis of variance (ANOVA) using the Statistical Package for the Social Sciences (SPSS) program, version 14 followed by least significant difference (LSD) to compare significance between groups (Armitage and Berry, 1987). The level of significance was set at $\mathrm{P}<0.05$. Percentage difference representing the percent of variation with respect to the corresponding control group was also calculated using the following formula:

$\%$ difference $=\frac{\text { Treated value }- \text { Control value }}{\text { Control value }} 100$

\section{Results}

\section{Biochemical data}

The results in Table (1) represented the influence of treatment with $R$. vesicarius extract on serum liver enzymes (AST, ALT, ALP and $\gamma$-GT) activity in HCC bearing rats. The HCC group showed significant elevation $(\mathrm{P}<0.05)$ in serum AST (49.79\%), ALT (98.85\%), ALP (133.43\%) and $\gamma$-GT $(173.17 \%)$ activity relative to the negative control group (Table 1). Treatment of the HCC group with $R$. vesicarius extract elicited significant reduction $(\mathrm{P}<0.05)$ in serum AST (-22.83\%), ALT (-30.9\%), ALP (-38.21\%) and $\gamma$-GT $(-24.28 \%)$ activity with respect to the untreated HCC group (Table 1).

The results depicted in Table (2) illustrated the influence of treatment with $R$. vesicarius extract on serum tumor markers (CEA, AFP and AFU), glypican 3, golgi 73 and VEGF levels in HCC bearing rats. The HCC group revealed significant increase $(\mathrm{P}<0.05)$ in serum CEA $(500 \%)$, AFP (111.05\%), AFU (275\%), glypican $3(63.68 \%)$, golgi $73(39.393 \%)$ and VEGF (41.06\%) levels in comparison with the negative control group. In contrast, treatment of the HCC group with $R$. vesicarius

Table 1. Influence of Treatment with $R$. Vesicarius Extract on Serum Liver Enzymes Activity in HCC bearing rats

\begin{tabular}{lcccc}
\hline Parameter & AST (U/L) & ALT (U/L) & ALP (U/L) & $\gamma$-GT (U/L) \\
\hline Groups & & & & \\
Negative control & $84.0 \pm 1.53$ & $44.7 \pm 1.05$ & $109.5 \pm 7.11$ & $14.48 \pm 1.06$ \\
HCC group & $125.8 \pm 13.2^{\mathrm{a}}$ & $88.9 \pm 4.31^{\mathrm{a}}$ & $255.6 \pm 12.6^{\mathrm{a}}$ & $39.55 \pm 1.91^{\mathrm{a}}$ \\
& $(49.79 \%)$ & $(98.85 \%)$ & $(133.43 \%)$ & $(173.17 \%)$ \\
HCC+ R.vesicarius group & $97.1 \pm 2.14^{\mathrm{b}}$ & $61.5 \pm 1.66^{\mathrm{b}}$ & $157.9 \pm 9.68^{\mathrm{b}}$ & $29.95 \pm 1.56^{\mathrm{b}}$ \\
& $(-22.83 \%)$ & $(-30.9 \%)$ & $(-38.21 \%)$ & $(-24.28 \%)$ \\
\hline
\end{tabular}

*Data were expressed as means \pm standard error (SE) for 10 animals/group. 
Table 2. Influence of Treatment with $R$. vesicarius Exttact on Serum Tumor Markers (CEA, AFP and AFU) Levels, Glypican 3, Golgi 73 and VEGF Levels in HCC Bearing Rats

\begin{tabular}{|c|c|c|c|c|c|c|}
\hline $\begin{array}{l}\text { Parameter } \\
\text { Groups }\end{array}$ & $\begin{array}{c}\text { CEA } \\
(\mathrm{ng} / \mathrm{ml})\end{array}$ & $\begin{array}{c}\text { AFP } \\
(\mathrm{ng} / \mathrm{ml})\end{array}$ & $\begin{array}{c}\text { AFU } \\
(\mathrm{pg} / \mathrm{ml})\end{array}$ & $\begin{array}{c}\text { Glypican } 3 \\
\text { (pg/ml }\end{array}$ & $\begin{array}{l}\text { Golgi } 73 \\
(\mathrm{ng} / \mathrm{ml})\end{array}$ & $\begin{array}{l}\text { VEGF } \\
(\mathrm{ng} / \mathrm{L})\end{array}$ \\
\hline Negative control & $0.12 \pm 1.250 \times 10^{-2}$ & $19.03 \pm 1.52$ & $32.33 \pm 3.07$ & $2.96 \pm 0.18$ & $231.0 \pm 7.35$ & $91.66 \pm 2.61$ \\
\hline $\begin{array}{l}\mathrm{HCC} \\
\text { group }\end{array}$ & $\begin{array}{c}0.60 \pm 6.0 \times 10^{-2 a} \\
(500 \%)\end{array}$ & $\begin{array}{c}40.07 \pm 2.98^{a} \\
(111.05 \%)\end{array}$ & $\begin{array}{c}121.2 \pm 6.1^{\mathrm{a}} \\
(275 \%)\end{array}$ & $\begin{array}{c}4.85 \pm 0.13^{\mathrm{a}} \\
(63.68 \%)\end{array}$ & $\begin{array}{l}322.0 \pm 3.74^{\mathrm{a}} \\
(39.393 \%)\end{array}$ & $\begin{array}{c}129.3 \pm 2.09^{\mathrm{a}} \\
(41.06 \%)\end{array}$ \\
\hline $\begin{array}{l}\text { HCC+ R.vesicarius } \\
\text { group }\end{array}$ & $\begin{array}{c}0.25 \pm 1.20 \times 10^{-2 b} \\
(-57.5 \%)\end{array}$ & $\begin{array}{c}30.44 \pm 0.41^{b} \\
(-24.08 \%)\end{array}$ & $\begin{array}{c}65.83 \pm 2.66^{b} \\
(-45.7 \%)\end{array}$ & $\begin{array}{l}3.63 \pm 0.2^{b} \\
(-25.02 \%)\end{array}$ & $\begin{array}{c}284.1 \pm 9.62^{b} \\
(-11.75 \%)\end{array}$ & $\begin{array}{c}100.76 \pm 3.8^{b} \\
(-22.08 \%)\end{array}$ \\
\hline
\end{tabular}

*Data were expressed as means \pm standard error (SE) for 10 animals / group, ${ }^{\text {a }}: \mathrm{P}<0.05$ vs negative control; b: $\mathrm{P}>0.05$ vs $\mathrm{HCC}$ group

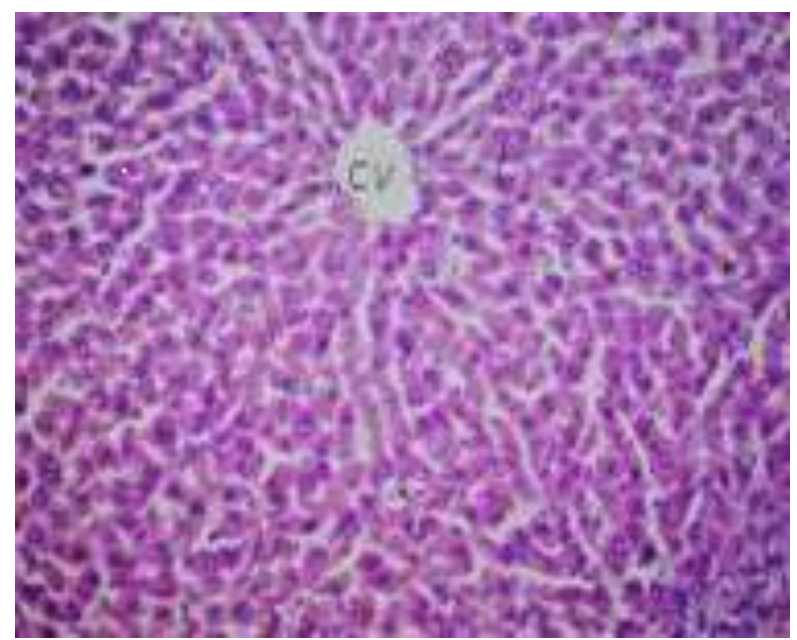

Figure 1. Photomicrograph of Liver Tissue Section of Rat in the Negative Control Group Showing Normal Histological Structure of the Central Vein and the Surrounding Hepatocytes in the Hepatic Parenchyma (H\&E x 40)

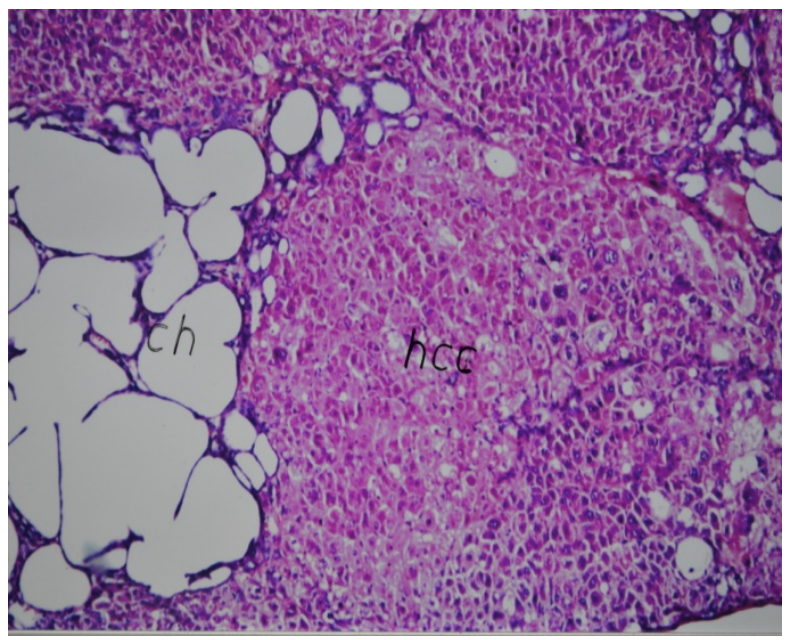

Figure 2. Photomicrograph of liver Tissue Section of rat in HCC Group Showing Foci of Anaplastic Hepatocellular Carcinoma with Other Foci of Cystic Cholangio Carcinoma (ch) (H\&E x 16)

extract resulted in significant decrease $(\mathrm{P}<0.05)$ in serum CEA (-57.5\%), AFP (-24.08\%), AFU (-45.7\%), glypican $3(-25.02 \%)$, golgi $73(-11.75 \%)$ and VEGF (-22.08\%) levels as compared to the untreated HCC group (Table 2).

Histopathological findings

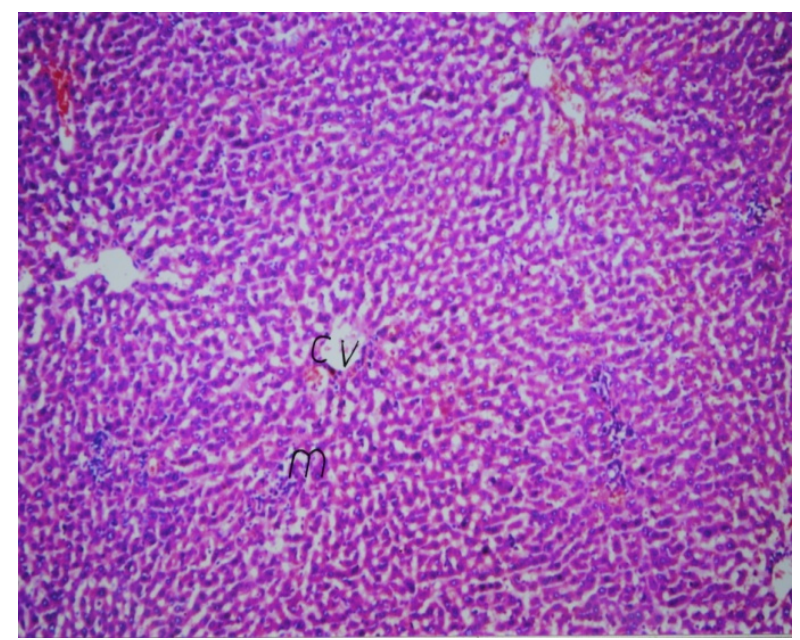

Figure 3. Photomicrograph of Liver Tissue Section of rat in HCC Group Treated with $R$. vesicarius Extract Showing Very Few Inflammatory Cells Infiltration in between the Hepatocyte (H\&E x 16)

Photomicrograph of liver tissue section of rat in the negative control group showed no evidences for histopathological alteration and the normal structural organization of the central vein and the surrounding hepatocytes in the hepatic parenchyma is observed (Figure 1). Photomicrograph of liver tissue section of rat in HCC group revealed hepatic parenchyma with foci of anaplastic hepatocellular carcinoma as well as other foci of cystic cholangio carcinoma associated with areas of telangictasis with haemorrhage. Also, individual hepatocellular necrosis is noted in the micrograph of a cross-sectioned liver tissue of rat in HCC group (Figure 2). Photomicrograph of liver tissue section of rat in HCC group treated with $R$. vesicarius extract showed no evidence of anaplasia but very few inflammatory cells infiltration in the hepatic parenchyma were observed (Figure 3).

\section{Discussion}

Chemical induction of liver carcinogenesis in the experimental animals initiated by the potent hepatocarcinogen diethylnitrosamine (NDEA) has been considered as one of the most accepted and widely used experimental model. This model closely mimics a subclass of human hepatocellular carcinoma (HCC) to study hepatocarcinogenesis and to allow screening of the potential anti-cancer agents on various phases of 
Significance of Rumex Vesicarius as Anticancer Remedy against Hepatocellular Carcinoma: an Experimental Animal Study

neoplastic disease (Chakraborty et al., 2007). The present study results demonstrated that HCC group showed significant elevation in serum AST, ALT, ALP and $\gamma$-GT activity versus to the negative control group. Significant elevation of serum AST and ALT activities were seen in a variety of liver conditions, including viral infection, cirrhosis, non-alcoholic steatohepatitis (NASH), drug toxicity, liver tissue degeneration and necrosis (Yang et al., 2009). AST elevations often predominate in patients with cirrhosis and even in liver diseases that typically have increased ALT level (Green and Flamm, 2002). Concerning ALP, it has been found that ALP among liver function tests, in addition to other tumor characters is an independent factor for disease-free survival and overall survival (Tong et al., 2010). Recent studies have suggested that preoperative ALP levels could be utilized to monitor and predict recurrence in high risk $\mathrm{HCC}$ patients (Kim et al., 2013). Regarding $\gamma$-GT, it is well established that the elevated serum $\gamma$-GT activity is associated with diseases of the liver, biliary system, pancreas, and different types of cancers including HCC (Fentiman, 2012). Experimental studies have shown that $\gamma$-GT was strikingly activated during the course of hepatocarcinogenesis induced by several hepatocarcinogens in animals (Fiala and Fiala, 1973). Chemical carcinogens may initiate some systematic factors that induce $\gamma$-GT synthesis (Vanisree and Shyamaladevi, 1998). The elevated values of $\gamma$-GT reflect the progress of carcinogenesis, since its activity correlates with tumor growth rate, differentiation and survival of the host (Koss and Greengurd, 1982).

The current data indicated that treatment of HCC group with $R$. vesicarius extract elicited significant reduction in serum AST, ALT, ALP and $\gamma$-GT activity relative to the untreated HCC group. These results are in agreement with Chen (2010) and Saleem et al. (2014) who reported that R. dentatus significantly controlled the elevation of liver enzymes. This hepatoprotective action is possibly ascribed to the presence of many active constituents. $\mathrm{R}$. dentatus active ingredients include chlorogenic acid, quercetin, myricitin, vitamin $\mathrm{C}$ and kaempferol. Among these isolated constituents, myrecitin (Rashed et al., 2013), quercetin (Janbaz et al., 2004) and kaempherol (Song et al., 2003), have been reported to have hepatoprotective activity. Of particular interest, quercetin, the active compound of $R$. vesicarius offered a multimechanistic approach in its protective effect against liver injury induced by ethanol in rats (Chen, 2010).

In the current work, that HCC group showed significant elevation in serum CEA, AFP and AFU levels in comparison with the negative control group. CEA is an important tumor-associated antigen, and its overexpression has been used to identify or diagnose early colorectal, gastric, pancreatic, ovarian cancer and others (Ladd et al., 2009). Li et al. (2008) reported that when the rat liver tumor induced by DENA appeared, the CEA content in serum elevated. It has long been recognized that exposure of rats to certain carcinogens like NDEA causes an elevation of circulating AFP levels (Sell et al., 1983) and the reproduction of AFP in adults is associated with hepatocellular carcinoma. This finding is greatly supported by the study of Liu et al (2012), Ahmed et al.
(2013), and Song et al. (2013). The upregulation of AFP gene expression in NDEA-challenged rats might be due to necrosis of hepatocytes caused by NDEA. Hepatocyte localization within or outside the liver plate is the defining factor that regulates the activity of AFP synthesis on a cellular level (Lazarevich, 2000). Although the precise mechanism of this regulation is not fully understood but the possible explanation for the reinitiation of AFP synthesis by neoplastic hepatocytes includes either increased transcription of AFP gene or post-translational modification affecting AFP production (Motalleb et al., 2008).

Alpha L-fucosidase (AFU) activity in serum was found to be significantly increased in HCC group as shown in the present work. This result comes in line with the previous study of Chen et al. (2012). The exact mechanism behind the increased AFU in HCC is presently unknown, but the possible mechanism for that increase seems to be due to the increased synthesis of proteins by tumor with a consequent increase in fucose turnover (Deugnier, 1984). This hypothesis is supported by experimental data which revealed $(i)$ elevated levels of fucose and fucosyltransferase activity in rat hepatoma tissue when compared to nontumor adjacent liver and (ii) disturbances in plasma membrane fucoderivative leading to an increase in fucoprotein levels (Vischer and Reutter, 1978) and (iii) the presence of abnormal fucogagliosides in hepatoma tissue (Holmes and Hakomori, 1982). One study showed the increased level of fucose in NDEA-treated rats when compared with control rats. (Balamurugan, 2011). Elevation in fucose content in the liver tissue of cancer patients have also been reported by some investigators and it has a considerable interest because of its potential application as diagnostic and/or prognostic marker. Biochemical studies have shown that changes in fucose content appears to be associated with tumor progression rather than with malignant transformation (Li et al., 1995).

In view of our data, the treatment of the HCC group with $R$. vesicarius extract led to significant decrease in serum CEA, AFP and AFU levels as compared to the untreated HCC group. Reporter assays indicated that plants belonging to genus $R$. vesicarius possessed antitumor activity for different tumor cell lines including colon, ovary, melanoma, breast, central nervous system and gastric cancer. These authors related this effect to the antiproliferative activity of these plants. The antiproliferative activity of $R$. vesicarius could be attributed to its content of polyphenols (Zhang et al., 2012) including quercetin and myricetin compounds. Quercetin is a potential anticancer, flavonoid molecule with ubiquitous nature. The suggested mechanisms for the chemopreventive action of quercetin include its capability to suppress cell proliferation and angiogenesis in cancer cells (Masuku et al., 2014). Moreover, quercetin was found to inhibit progression of human breast MCF-7 cancer cells through down regulation of proteins CDK2, cyclin A, D, E, p53 and p57 involved in cell cycle, resulting in the arrest of cell cycle. Also, quercetin has been reported to block cell cycle at G2/M through up-regulation of p21 and cyclin $\mathrm{B}$ to regulate cell cycle arrest at the $\mathrm{G} 1$ phase and $\mathrm{G} 2 / \mathrm{M}$ phase in breast cancer cell lines (Moon et al., 2008). It was 
also found that quercetin initiated apoptosis in cancer cells via the mitochondrial pathway involves the activation of caspase-3 downstream from caspase-9 (Aalinkeel et al., 2008). In addition, the antitumor efficacy of $R$. vesicarius is possibly ascribed to the synergies between quercetin and myricetin. Myricetin has been found to inhibit 7,12-dimethylbenz(a)-anthracene, benzo[a]pyrene and $\mathrm{N}$-methyl-N-nitrosourea-induced tumor formation in a skin tumorigenesis model (Mukhtar etal., 1988).

In light of our data, HCC group showed significant elevation in serum glypican 3 (GPC 3) and golgi 73 (GP 73) levels in respect to the negative control group. Coston et al. (2008) demonstrated the sensitivity and specificity of GPC 3 for HCC by $88 \%$ and $97 \%$, respectively. GPC3 is a very specific marker not only for differentiating HCC from non hepatic tumors with epithelial differentiation, but also for differentiating HCC from hepatic adenoma (HA) and focal nodular hyperplasia (FNH). Golgiprotein-73 (GP73) is a resident Golgi glycoprotein expressed in epithelial human cells. GP73 serum levels are higher in early HCC patients than in cirrhotic patients. Serum GP73 is dramatically elevated in patients with HCC, and the sensitivity and specificity of GP73 for HCC might be superior to those of AFP (Willyard, 2007). It is considered as a possible tumor marker for HCC and indeed it shows a specificity of $75 \%$ and a sensitivity of $69 \%$ (Malaguarnera et al., 2010).

Treatment of the HCC group with $R$. vesicarius extract experienced significant decrease in serum GPC 3 and GP 73 serum levels relative to the untreated HCC group as shown in the present study. It is believed that oxidative stress plays critical roles in the initiation and progression of hepatocarcinogenesis. It has been hypothesed that polymorphisms that impair anti-oxidative capacity may influence HCC risk. Moreover, reactive oxygen species have been related to the aetiology of cancer as they are known to be mitogenic and therefore capable of tumour promotion. Thus, it is possible that cumulative defects in protection from oxidative stress may result in increased risk of liver cancer in the Moroccan population (Ezzikouri et al., 2010). R. vesicarius species have been studied as potential anticarcinogens because of their flavonoids content which stimulate apoptosis, inhibit proliferation and show antioxidant activity (Ramos, 2008).

In the present work, serum VEGF level of rats in HCC group showed significant increase which is in consistent with the results of Shahat et al. (2012). This finding indicated the high angiogenic activity in rats bearing HCC induced by NDEA. Earlier report by Jozkowicz and co-workers indicated the increased nitric oxide level in NDEA treated animals which enhances the angiogenesis by stimulating the synthesis of VEGF (Jozkowicz et al., 2001). NDEA administration has been found to increase nitric oxide synthase-2 (NOS2) activity indicating the generation of reactive oxygen species (ROS), promoting carcinogenesis and possibly leading towards angiogenesis. It seems that more advanced stage tumors actually express higher levels of VEGF protein. It has been shown that high expression levels of VEGF mRNA and protein in lung cancer patients is correlated with advanced lung cancer stage (Fontanini et al., 1997).
The present data demonstrated that the treatment of the HCC group with $R$. vesicarius extract produced significant reduction in serum VEGF level in comparison with the untreated HCC group. Accumulated evidences have suggested that some of $R$. vesicarius species could inhibit VEGF expression (Mirzoeva et al., 2008) and tumor angiogenesis in vivo (Fang et al., 2007). VEGF is highly stimulated by hypoxia-inducible factor 1 (HIF-1), a transcription factor that consists of two subunits, HIF-1a and HIF-1b (Powis, 2004). Several studies demonstrated that most flavonoids could inhibit HIF-1a and/or VEGF expression (Buchler et al., 2004; Fang et al., 2005; Fu et al., 2007) as well as VEGF-mediated angiogenic signalling in tumoral cells (Bagli et al., 2004). Therefore, it is assumed that flavonoids affected VEGF expression by reducing HIF- 1a intracellular protein levels (Anso et al., 2010).

Photomicrograph of liver tissue section of HCC group showed hepatic parenchyma with foci of anaplastic hepatocellular carcinoma as well as other foci of cystic cholangio carcinoma associated with areas of telangictasis with haemorrhage as well as individual hepatocellular necrosis. These remarkable features of hepatocellular carcinoma are in agreement with the studies of Abdallah and Khattab, (2004) and Seufi et al. (2009). It has been reported that histological examination of liver tissue of HCC group showed inflammatory cells infiltration and fibroblastic cells proliferation that divided the cancer and necrosed hepatocytes of the parenchyma into nodules with hyperchromatic nuclei as well as cellular pleomorphism and polarity (Seufi et al., 2009). Photomicrograph of liver tissue section of HCC group treated with $R$. vesicarius extract showed very few inflammatory cells infiltration in the hepatic parenchyma. In accordance of our results Saleem et al. (2014) reported that animals treated with aqueous methanolic extract of R. dentatus showed almost normal hepatocytes and normal structural organization of the liver.

The present setup provided experimental evidences that $R$. vesicarius possessed a promising anticancer potential against HCC induced in rats. This effect could be related to its hepatoprotective properties, potent antiangiogenic activity and effective antiproliferative potential as well.

\section{Acknowledgements}

The authors would like to extend their sincere appreciation to the Deanship of Scientific Research at King Saud University for funding of this research through the Research Group Project no. RGP-VPP-262.

\section{References}

Aalinkeel R, Bindukumar B, Reynolds JL (2008). The dietary bioflavonoid, quercetin, selectively induces apoptosis of prostate cancer cells by down-regulating the expression of heat shock protein 90. Prostate, 68, 1773-89.

Abdallah IZ, Khattab HA (2004). Protective role of lycopene against diethylnitrosamine induced experimental hepatocarcinogenesis. Egypt J Hosp Med, 16, 1-13.

Abou Elfotoh A, Shams A, Anthony P, et al (2013). Lipophilic 
Significance of Rumex Vesicarius as Anticancer Remedy against Hepatocellular Carcinoma: an Experimental Animal Study

constituents of Rumex vesicarius L. and Rumex dentatus L. Antioxidants, 2, 167-80.

Ahmed HH, Shousha WG, El-Mezayen HA, et al (2013). In vivo antitumor potential of carvacerol against hepatocellular carcinoma in rat moderl. World J Pharm Pharmaceut Sci, 2, 2367-96.

Ahmed MM, Aleisa AM, Al-Rejaie SS, et al (2010). Thymoquinone attenuates diethylnitrosamine induction of hepatic carcinogenesis through antioxidant signaling. Oxid Med Cell Longev, 3, 254-261.

Anso E, Zuazo A, Irigoyen M, et al (2010). Flavonoids inhibit hypoxia-induced vascular endothelial growth factor expression by a HIF-1 independent mechanism. Biochem Pharmacol, 79, 1600-9

Armitage P, Berry G (1987). Comparison of several groups. in, statistical method in medical research. $2^{\text {nd }}$ ed., Oxford; blockwell significant publication, pp.186-213.

Bagli E, Stefaniotou M, Morbidelli L, et al (2004). Luteolin inhibits vascular endothelial growth factor-induced angiogenesis; inhibition of endothelial cell survival and proliferation by targeting phosphatidylinositol 30-kinase activity. Cancer Res, 64, 7936-46.

Balamurugan K (2011). Molecular investigation on the efficacy of luteolin as a potent therapeutic agent for experimentally induced hepatocellular carcinoma in wistar albino rats. $\mathrm{PhD}$. thesis, university of prist, vallam, thanjavur - 613403.

Banchroft JD, Stevens A, Turner DR (1996). Theory and Practice of histological techniques. $4^{\text {th }}$ ed., New York, London, San Francisco, Tokyo; churchill livingstone.

Barbosa-Filho JM, Alencar AA, de Andrade Tomaz AC, et al (2008). Sources of alpha-, beta-, gamma-, delta- and epsiloncarotenes, a twentieth century review. Brazil J Pharma, 18, 135-54.

Bishayee A. (2012). Recent advances in the prevention and therapy of hepatocellular carcinoma. Current Cancer Drug Targets, 12, 1043-4.

Buchler P, Reber HA, Buchler MW, et al (2004). Antiangiogenic activity of genistein in pancreatic carcinoma cells is mediated by the inhibition of hypoxia-inducible factor- 1 and the downregulation of VEGF gene expression. Cancer, 100, 201-10.

Center MM, Jemal A (2011). International trends in liver cancer incidence rates. Cancer Epidemiol Biomarkers Prev, 20, 2362-8.

Chakraborty T, Chatterjee A, Rana A, et al (2007). Carcinogeninduced early molecular events and its implication in the initiation of chemical hepatocarcinogenesis in rats, chemopreventive role of vanadium on this process. Biochim Biophys Acta, 1772, 48-59.

Chen B, Ning M, Yang G (2012). Effect of Paeonol on antioxidant and immune regulatory activity in hepatocellular carcinoma rats. Molecules, 17, 4672-83.

Chen X (2010). Protective effects of quercetin on liver injury induced by ethanol. Pharmacogn Mag, 6, 135-141.

Coston WM, Loera S, Lau SK, et al (2008). Distinction of hepatocellular carcinoma from benign hepatic mimickers using Glypican-3 and CD34 immunohistochemistry. Am J Surg Pathol, 32, 433-44.

Darwish HA, El-Boghdady NA (2011). Possible involvement of oxidative stress in diethylnitrosamine induced hepatocarcinogenesis, chemopreventive effect of curcumin. J Food Biochem, 37, 353-61.

Deuffic-Burban S, Mohamed MK, Larouza B, et al (2006). Expected increase in hepatitis C-related mortality in Egypt due to pre-2000 infections. Hepatol J, 44, 455-61.

Deugnier Y (1984). Serum $\alpha$-L-fucosidase, A new marker for the diagnosis of primary hepatic carcinoma. Hepatol, 4, 889-92.

ECCLS (1989). Determination of the catalytic activity concentration in serum on L-aspartate aminotransferase (AST). Clin Chem, 20, 204-11.

El-Bakry AA, Mostafa HAM, Alam EA (2012). Antioxidant activity of $R$. vesicarius at the vegetative stage of growth. Asian J Pharm Clin Res. 5, 111-7.

El-Serag HB, Rudolph KL (2007). Hepatocellular carcinoma, epidemiology and molecular carcinogenesis. Gastroenterol, 132, 2557-76.

El-Serag HB (2002). Hepatocellular carcinoma, an epidemiologic view. J Clin Gastroenterol, 35, 72-8.

El-Shahat M, El-Abda S, Alkafafyb M, et al (2012). Potential chemoprevention of diethylnitrosamine-induced hepatocarcinogenesis in rats, Myrrh (Commiphora molmol) vs. turmeric (Curcuma longa). Acta Histochemica, 114, 421-8.

Ezzikouri S, El Feydi AE, Afifi R, et al (2010). Polymorphisms in antioxidant defence genes and susceptibility to hepatocellular carcinoma in a Moroccan population. Free Radic Res, 44, 208-16.

Fang J, Xia C, Cao Z, et al (2005). Apigenin inhibits VEGF and HIF- 1 expression via PI3K/AKT/p70S6K1 and HDM2/p53 pathways. FASEB J, 19, 342-53.

Fang J, Zhou Q, Liu LZ, et al (2007). Apigenin inhibits tumor angiogenesis through decreasing HIF-1alpha and VEGF expression. Carcinogenesis. 28, 858-64.

Fentiman IS (2012). Gamma-glutamyl transferase, risk and prognosis of cancer. Br J Cancer, 106, 1467-8.

Fiala S, Fiala ES (1973). Activation by chemical carcinogen of gamma glutamyl transpeptidase in rat and mouse liver. $J$ Natl Cancer Inst, 51, 151-8.

Fontanini G, Vignati S, Boldrini L, et al (1997). Vascular endothelial growth factor is associated with neovascularization and influences progression of non-small cell lung carcinoma. Clin Cancer Res, 3, 861-5.

Fu B, Xue J, Li Z, et al (2007). Chrysin inhibits expression of hypoxiainducible factor-1alpha through reducing hypoxiainducible factor-1alpha stability and inhibiting its protein synthesis. Mol Cancer Ther, 6, 220-226.

Gao J, Xie L, Yang WS (2012). Risk factors of hepatocellular carcinoma current status and perspectives. Asian Pac J Cancer Prev, 13, 743-52.

Green RM, Flamm S (2002). AGA technical review on the evaluation of liver chemistry tests. Gastroenterol, 123, 1367-84.

Hirai H (1982). Alpha fetoprotein. In , Chu T M, ed. Biochemical Markers for Cancer. New York, marcel dekker, 23-59.

Holmes EH, Hakomori SI (1982). Isolation and characterization of a new fucoganglioside accumulated in precancerous rat liver and in rat hepatoma induced by N-2- acetylaminofluorene. J Biol Chem, 257, 7698-703.

Hosny G, Farahat N, Tayel H, Hainaut P (2008). Ser-249 TP53 and CTNNB1 mutations in circulating free DNA of Egyptian patients with hepatocellular carcinoma versus chronic liver diseases. Cancer Lett, 264, 201-8.

Imran M, Raja MM, Basith JA (2011). Determination of total phenol, flavonoid and antioxidant activity of edible mushrooms pleurotus florida and pleurotus eous. Int Food Res $J, \mathbf{1 8}, 574-7$.

Janbaz K, Saeed S, Gilani A (2004). Studies on the protective effects of caffeic acid and quercetin on chemical-induced hepatotoxicity in rodents. Phytomedicine, 11, 424-30.

Jozkowicz A, Cooke JP, Guevara I, et al (2001). Genetic augmentation of nitric oxide synthase increases the vascular generation of VEGF. Cardiovasc Res, 51, 773-83.

Khan TH. (2012). Soy diet diminish oxidative injure and early promotional events induced by $\mathrm{CCl} 4$ in rat liver. Int $J$ Pharmacol, 8, 30-8. 
Kim JM, Kwon CHD, Joh JW, et al (2013). The effect of alkaline phosphatase and intrahepatic metastases in large hepatocellular carcinoma. World J Surg Oncol, 11, 40.

Koss B, Greengurd O (1982). Effect of neoplasma on the content and activity of alkaline phosphatase and gamma glutamyl transpeptidase in uninvolved host tissues. Cancer Res, 42 , 2146-51.

Ladd, J, Lu H, Taylor AD (2009). Direct detection of carcinoembryonic antigen autoantibodies in clinical human serum samples using a surface plasmon resonance sensor. Colloids Surf B Biointerfaces, 70, 1-6.

Lakshmi CP, Chakradhar RPS, Rao JL, et al (2009). EPR and IR spectral investigations on some leafy vegetables of Indian origin. Spectrochimica Acta Part A, 74, 140-7.

Lazarevich NL (2000). Review, molecular mechanisms of alphafetoprotein gene expression. Biochemistry, 65, 117-33.

Li CJ, Wang C, Padee AB (1995). Induction of apoptosis by beta-lapachone in human prostate cancer cells. Cancer Res, $\mathbf{5 5}, 3712-5$

Li N, Xiao B, Chen XB (2008). Relationship between expression of CEA, E-cadherin and liver metastasis in colorectal cancer. Chin J Clin Oncol, 5, 429-32.

Liao DJ, Blanck A, Eneroth P, et al (2001). Diethylnitrosamine causes pituitary damage, disturbs hormone levels, and reduces sexual dimorphism of certain liver functions in the rat. Environ Health Perspect, 109, 943-7.

Liu JG, Zhao HJ, Liu YJ, Et al (2012). Effect of two selenium sources on hepatocarcinogenesis and several angiogenic cytokines in diethylnitrosamine-induced hepatocarcinoma rats. J Trace Elem Med Biol, 26, 255-61.

Lyer P, Zekri AR, Hung CW, et al (2010). Concordance of DNA methylation pattern in plasma and tumor DNA of Egyptian hepatocellular carcinoma patients. Exp Mol Pathol, 88, 107-11.

Malaguarnera G, Giordano M, Paladina I, et al (2010). Serum markers of hepatocellular carcinoma. Dig Dis Sci, 55, 2744-55

Masuku SKS, Owaga EE, Gadaga TH, et al (2014). Molecular mechanism of the effects of quercetin on human breast cancer cells. Direct Res J Health Pharmacol, 2, 6-9.

Matkowski A (2008). Plant in vitro culture for the production of antioxidants-a review. Biotechnol Adv, 26, 548-60.

Mirzoeva S, Kim ND, Chiu K, et al (2008). Inhibition of HIF1 alpha and VEGF expression by the chemopreventive bioflavonoid apigenin is accompanied by Akt inhibition in human prostate carcinoma PC3-M cells. Mol Carcinog, 47, 686-700.

Mitupatum T, Aree K, Kittisenachai S, et al (2015). Hep88 mAb-mediated paraptosis-like apoptosis in HepG2 cells via downstream upregulation and activation of caspase-3, caspase-8 and caspase-9. Asian Pac J Cancer Prev, 16, 1771-9

Moon YJ, Shin BS, An G, et al (2008). Biochanin A inhibits breast cancer tumor growth in a murine xenograft model. Pharm Res. 25, 2158-63.

Motalleb G, Hanachi P, Fauziah O, et al (2008). Effect of Berberis vulgaris fruit extract on alpha-fetoprote in gene expression and chemical carcinogen metabolizing enzymes activities in hepatocarcinogenesis rats. Iran J Cancer Prev, 1, 33-44.

Mukhtar H, Das M, Khan WA, et al (1988). Exceptional activity of tannic acid among naturally occurring plant phenols in protecting against 7,12-dimethylbenz(a)anthracene-, benzo(a)- pyrene-, 3-methylcholanthrene-, and N-methyl$\mathrm{N}$-nitrosourea-induced skin tumorigenesis in mice. Cancer Res. 48, 2361-5.

Powis G, Kirkpatrick L (2004). Hypoxia inducible factor-1alpha as a cancer drug target. Mol Cancer Ther, 3, 647-54.
Raghavendra M, and Reddy AKG (2011). Acute and chronic toxicity studies of ethanolic extract of Rumex vesciscarius L. in experimental animals. $J S c i, 1,16-20$

Ramos S (2008). Cancer chemoprevention and chemotherapy, dietary polyphenols and signalling pathways. Mol Nutr Food Res. 52, 507-52.

Rashed KN, Chang CW, Wu LY, et al (2013). Hepatoprotective activity of Diospyros lotus fruits on acute liver injury induced by carbon tetrachloride and phytochemical analysis. Topcls J Herb Med, 2, 75-83.

Saleem M, Ahmed B, Karim M, et al (2014). Hepatoprotective effect of aqeous methanolic extract of Rumex dentatus in paracetamol-induced hepatotoxicity in mice. Bangladesh $J$ Pharmacol, 9, 284-9

Schwartz MK (1987). Tumor markers in diagnosis and screening . In, Ting SW, Chen JS, Schwartz MK, eds. human tumor markers, amsterdam, elsevier science, 3-16.

Sell S, Becker F, Leffert HL, et al (1983). $\alpha$-Fetoprotein as a marker for early events and carcinoma development during chemical hepatocarcinogenesis. Environ Sci Res, 29, 271-93.

Seufi A, Safinz S, Ibrahim S, et al (2009). Preventive effect of the flavonoid, quercetin, on hepatic cancer in rats via oxidant/ antioxidant activity, molecular and histological evidences. $J$ Exp Clin Canc Res, 28, 80-6.

Shahat AA, Alsaid MS, Alyahya MA, et al (2013). NAD(P)H, quinoneoxidoreductase 1 (NQO1) Inducer activity of some saudi arabian medicinal plants. Planta Medica, 79, 459-64

Song EK, Kim JH, Kim JS, et al (2003). Hepatoprotective phenolic constituents of Rhodiola sachalinensis on tacrineinduced cytotoxicity in Hep G2 cells. Phytother Res, 17, 563-65.

Song Y, Jin S, Cui L, et al (2013). Immunomodulatory effect of Stichopus japonicus acid mucopolysaccharide on experimental hepatocellular carcinoma in rats. Molecules, 18, 7179-93.

Thomas MB, Jaffe D, Chotietal MM (2010). Hepatocellular carcinoma, consensus recommendations of the National Cancer Institute Clinical Trials Planning Meeting. Clinical Oncol, 28, 3994-4005.

Tietz NW (1995). Clinical guide to laboratory Tests, $3^{\text {rd }}$ ed AACC.

Tong MJ, Chavalitdhamrong D, Lu DSK, et al (2010). Survival in Asian Americans after treatments for hepatocellular carcinoma, a seven-year experience at UCLA. J Clin Gastroenterol, 44, 63-70.

Vanisree AJ , Shyamaladevi CS (1998). Effect of therapeutic strategy established by $\mathrm{N}$-acetyl cystine and vitamin $\mathrm{C}$ on the activities of tumour marker enzymes in vitro. Ind $J$ Pharmacol, 31, 275-8.

Vischer P, Reutter W (1978). Specific alterations of fucoprotein biosynthesis in the plasma membrane of Morris hepatoma 7777. Eur J Biochem, 84, 363-8.

Willyard C (2007). Researchers look for 'sweet' method to diagnose cancer. Nat Med, 13, 1267

Yang R-Z, Park S, Reagan WJ, et al (2009). Alanine aminotransferase isoenzymes, molecular cloning and quantitative analysis of tissue expression in rats and serum elevation in liver toxicity. Hepatol, 49, 598-607.

Zeng YW, Du J, Pu XY, et al (2015). Coevolution between human's anticancer activities and functional foods from crop origin center in the world. Asian Pac J Cancer Prev, 16, $2119-28$

Zhang H, Guo Z, Wu N, et al (2012). Two novel naphthalene glucosides and an anthraquinone isolated from rumex dentatus and their antiproliferation activities in four cell lines. Molecules, 17, 843-50. 